\title{
Cervical Function Alteration
}

National Cancer Institute

\section{Source}

National Cancer Institute. Cervical Function Alteration. NCI Thesaurus. Code C40929.

Cervical Function Alteration involves a change in the quality of the existing biochemical composition or functionality of the cervix. 